\title{
Towards Discovering the Sentiment Holder in Arabic Text
}

\author{
Mohammed Dahab \\ King Abdulaziz University \\ Faculty of Computing and Information Technology \\ Jeddah, Saudi Arabia
}

\begin{abstract}
Sentiment analysis is consider with extracting specific subjective information from reliable amounts of text. Sentiment analysis holder recognition is approach that has not been considered yet in Arabic Language. This approach essentially requires deep understanding of sentences structures. This paper presents survey for the sentiment analysis operations, classifications and summarization. And proposed sentiment holder Algorithm for extract the holder in Arabic sentences.
\end{abstract}

\section{Keywords}

Sentiment analysis, Holder, Opinion mining, Arabic.

\section{INTRODUCTION}

Sentiment Analysis is considered with determining and extracting the stance of a subject. Sentiment Analysis is based on document, where the sentiment inside the document is summarized as positive, negative or objective, as well as sentence based, where Particular sentences. extracted sentiments in the text are classified.

Sentiment Analysis can be identified as the analysis of opinions: an opinion is an specific statement by "holder" on specific "topic" that is expressed with available sentiment.[4] It is also includes several sub operations, such as subjectivity detection, polarity classification, review summarization, humor detection, emotion classification, and sentiment transfer.[7]

The term sentiment analysis is frequently used, but in researches both sentiment analysis and opinion mining are usually engaged. They mostly represent the same field of study but the concepts are not equivalent. The paper distinguish and show the difference between them later. Sentiment analysis and opinion mining mainly focuses on opinions which express or involve positive or negative sentiments.[7]

\section{SENTIMENT ANALYSIS RESEARCHES}

The sentiment analysis is highly testing as a Natural Language Processing (NLP) research topics, And developed quickly to become one of the mainly active research areas in NLP. It is also commonly researched in data mining, Web mining, and information retrieval. sentiment analysis has been discussed at three levels:

Document level: This level is to specify whether a entire sentiment document expresses a positive or negative sentiment. This level is generally known as sentiment classification. This level each document extract sentiment $\mathrm{s}$ on a specific entity.

Sentence level: This level goes to the sentences and specify in each sentence expressed a positive, negative, or neutral sentiment . Neutral means no sentiment. This level of analysis

\author{
Salma Al Asmari \\ King Abdulaziz University \\ Faculty of Computing and Information Technology \\ Jeddah, Saudi Arabia
}

is closely related to subjectivity classification when extract sentences called "objective sentences" that extract real information from sentences called "subjective sentences" that extract subjective sentiment $\mathrm{s}$. we should know that subjectivity is not the same as sentiment because many objective sentences can involve sentiments.

Entity and Feature level: This level is not determine which the person liked or did not like for the document level and the sentence level but the feature level describe good detailed analysis. Feature level also called "sentiment summarization"

Feature level is not looks for language constructs documents, paragraphs, sentences. It exactly looks for the specific sentiment. It is depends on that an sentiment consists of a sentiment positive or negative and the target of the sentiment .

An sentiment without it is target being identified of limited use. Understanding the meaning of sentiment targets also lets us understand the sentiment analysis. For example, although the sentence “ بالر غم من أن الخدمة ليست جيدة , سأظل أحب هذا "Although the service was not good, But I will still love this restaurant "obviously has a positive nature, This sentence is not completely positive. The sentence is positive about "المطعم","The restaurant", but negative about "The service".[8]

The problem that occurs in current Sentiment Analysis approaches is the inaccurate classification of sentiment topics. In a lot of recent Sentiment Analysis systems such as Opinion crawl, Sentiment 140 and Social mention, the user is encouraged to just insert a topic to get a sentiment. Then the system returns a list of sentiments on the particular topic. For example, one user might searching for opinions about " "مصطفى محمود "Mustafa Mahmud", and extract several results related to "مصطفى محمود","Mustafa Mahmud" is Philosopher and doctor and Egyptian writer.[9]

\section{RELATED WORK}

Most existing Sentiment Analysis approaches ignore the topic detection operation because they center of attention on the identification of sentiment features and on the analysis of the nature of the sentiment.[4]

There are Several works for example:

- Weakly supervised joint sentiment-topic.

- Detection from text, Relational features in finegrained opinion analysis.

- Modeling online reviews with multi-grain topic models.

- Leveraging sentiment analysis for topic detection.

It focused on the topic detection as an essential operation for improving sentiment analysis, It is not focusing on the topic detection operation itself, they consist of topics within their 
models. The sentiment holder extraction, compares three different methods based on classifiers for holder extraction and proposes a novel method for addressing the fewer common case of sentiment holder . [4]

Sentiment holder extraction in Arabic language is presents work in Arabic Sentiment holder field. Sentiment source identification in Arabic language are explored using two approaches, it concludes sequential tagging ML classifiers outperform patterns in terms of recall and precision.[2]

\section{SENTIMENT ANALYSIS DEFINITION}

The following example about "التعليم الالكتروني", "Electronic Learning" to introduce the idea, id number is connected with each sentence for easy reference:

Written by: سارة علي "Sara Ali" Date: October 6, 2013

ق قمت بالتسجيل في التعليم الالكتروني منذ 4 أثشهر (1)

" I registered up in the e-learning 4 months ago "

(2) التعليم الالكثروني مطور و فعال .

" The e-learning developed and effective "

خدمة توفر المادة العلمية ممتازة (3) خمازة)

"The Service provides an excellent scientific course"

الاختبار ات الالكترونية كذلك موثقة (4) الكت

"Electronic exams is reliable too "

و الدي يقول عيبه عدم وجود تفاعل مباشر مع استاذتك (5)

"My father says the only lack is indirect interaction with your lecturer". I notice here a little necessary points:

1. The review has a number of sentiments, both positive and negative, about "التعليم الالكتروني", " Electronic Learning".

2. Sentence (2) expresses a positive sentiment about "التعليم الالكتروني" ,"Electronic Learning"

3. Sentence (3) expresses a positive sentiment about "توفر المادة العلمية" ,"The scientific course availability ".

4. Sentence (4) expresses a positive sentiment about "الاختبار ات الالكترونية","The electronic exams".

5. Sentence (5) expresses a negative sentiment about

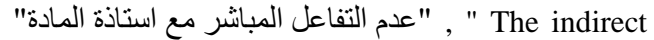
interaction with your lecturer".

From these sentiments, It easy to specify the following imperative notices: An sentiment consists of two key components: a goal $\mathrm{g}$ and a sentiment $\mathrm{s}$ on the goal, i.e.(g, s), where $\mathrm{g}$ can be any entity about the sentiment has been expressed, and s is a positive, negative, or neutral sentiment.

For example, the target of the sentiment in sentence (2) is "The electronic Learning" , and the target of the sentiment in sentence (3) is the "توفر المواد التعليمية","The scientific course availability". This example has sentiments from person which are called sentiment holders. The holder of the sentiments in sentences (2), (3), and (4) is the author of the review (") (") ("Sara Ali"), but for sentence (5), is (الو الد),(The father) of the author.
The date of the example is October 6, 2013. This date is necessary because to know how sentiments change through the time.[8]

\section{SENTIMENT ANALYSIS OPERATIONS}

After the definition, to present the objective and the operations of sentiment analysis. The Objective of sentiment analysis means: If there is an sentiment document $d$, to extract all sentiment elements $\left(\mathrm{E}_{\mathrm{i}}, \mathrm{A}_{\mathrm{ij}}, \mathrm{O}_{\mathrm{ijk}}, \mathrm{H}_{\mathrm{k}}, \mathrm{T}_{\mathrm{l}}\right)$ in $\mathrm{d}$. The operations are extracted from the 5 elements of the document. The first element is the entity, because the need to extract all the entities. To extract information the operation is called (named entity recognition) NER.

After extraction to identify the extracted entities. In natural language, the author sometimes write the same entity in various ways. For example, "سارة" may be written as "سارا" "ساره". So, It is necessary to identify that they all refer to the same entity.[4]

The entity model: An entity $E_{i}$ is implemented as a finite set of features $F_{i}=\left(F_{i 1}, F_{i 2}, \ldots, F_{i n}\right) . E_{i}$ can be implemented by any one of a finite set of its entity expressions $\left(\mathrm{E}_{\mathrm{i} 1}, \mathrm{E}_{\mathrm{i} 2}, \ldots\right.$, $\left.E_{i s}\right)$. Each feature $f_{i j} \in F_{i}$ of entity $E_{i}$ can be implemented by one of it is finite set of feature expressions $\left(\mathrm{fE}_{\mathrm{ij} 1}, \mathrm{fE}_{\mathrm{ij} 2}, \ldots\right.$, $\left.\mathrm{fE}_{\mathrm{ijm}}\right)$.

The sentiment document model: An sentiment document $d$ includes sentiments in set of entities $\left(\mathrm{e}_{1}, \mathrm{e}_{2}, \ldots, \mathrm{e}_{\mathrm{r}}\right)$ and a subset of their features from a set of sentiment holders $\left(h_{1}, h_{2}\right.$, $\left.\ldots, h_{p}\right)$. So, set of sentiment documents D, sentiment analysis includes of the next fundamental operations:

- The first operation is extract the entity and specify it: In document D to extract all entity expressions, and classify synonymous entity expressions into entity classifies. Every entity expression implements a specific entity $\mathrm{e}_{\mathrm{i}}$.

- The second operation is extract the feature and categorize it: To extract all feature expressions of the entities, and categorize the feature expressions into clusters. Each feature expression cluster of entity $e_{i}$ implements a specific feature $\mathrm{f}_{\mathrm{ij}}$.

- The third operation is extract the sentiment holder and categorize it: By extract the sentiment holders for sentiments from text and categorize them. The operation is also to the previous two operations.

- The fourth operation is extract the time and standardize it: By extract the times when sentiment are contain time formats. The operation is the same as the previous operations.

- The fifth operation classify the sentiment features: By determines is the sentiment in an feature $f_{i j}$ is positive, negative or neutral.

- The sixth operation generate the sentiment elements : By implements the results of the previous operations. It is possible to extracting all sentiment elements $\left(\mathrm{E}_{\mathrm{i}}, \mathrm{F}_{\mathrm{ij}}, \mathrm{O}_{\mathrm{ijkl}}, \mathrm{H}_{\mathrm{k}}\right.$, $\mathrm{T}_{1}$ ) exist in document $\mathrm{d}$. This operation is looked very easy but it is in fact very difficult in many cases and the next example to shows the difficulty. [8]

\section{SENTIMENT SUMMARIZATION}

The sentiment are basically subjective. One sentiment from a single sentiment holder is usually not enough for action. Although an sentiment summary can be in one of many forms, 
e.g., structured summary or short text summary, the key elements of a summary should include sentiment about different entities and their features.

The sentiment elements defined above actually to present a good basis of information and also a framework for generating both good quality and specific quantity summaries. A standard form of summary is depends on features and is called feature-based sentiment summary. When make a Questionnaire about "Electronic Learning التعليم الإلكتروني for group of students. The next table show summarized results.

\begin{tabular}{|c|c|c|}
\hline Negative & Positive & Sentiment \\
\hline 20 & 99 & التعليم الإلكتروني Electronic Learning \\
\hline 30 & 90 & التسجيل Registration \\
\hline 60 & 70 & Developed منطور \\
\hline 30 & 56 & المادة العلمية Course \\
\hline 70 & 80 & الإختبار ات الإلكترونية Electronic Exams \\
\hline 90 & 10 & وجود تفاعل مباشر Direct Interaction \\
\hline
\end{tabular}

Electronic Learning "التعليم الاكتروني":

Feature: "التعليم الالكتروني متطور و فعال" :" The e-learning

developed and effective "

Positive: 99 <Particular review sentences>

Negative: $20<$ Particular review sentences>

Feature: "توفر المادة العلمية", "The scientific course availability "

Positive: $56<$ Particular review sentences>

Negative: $30<$ Particular review sentences>

Figure 1. An feature-based sentiment summary

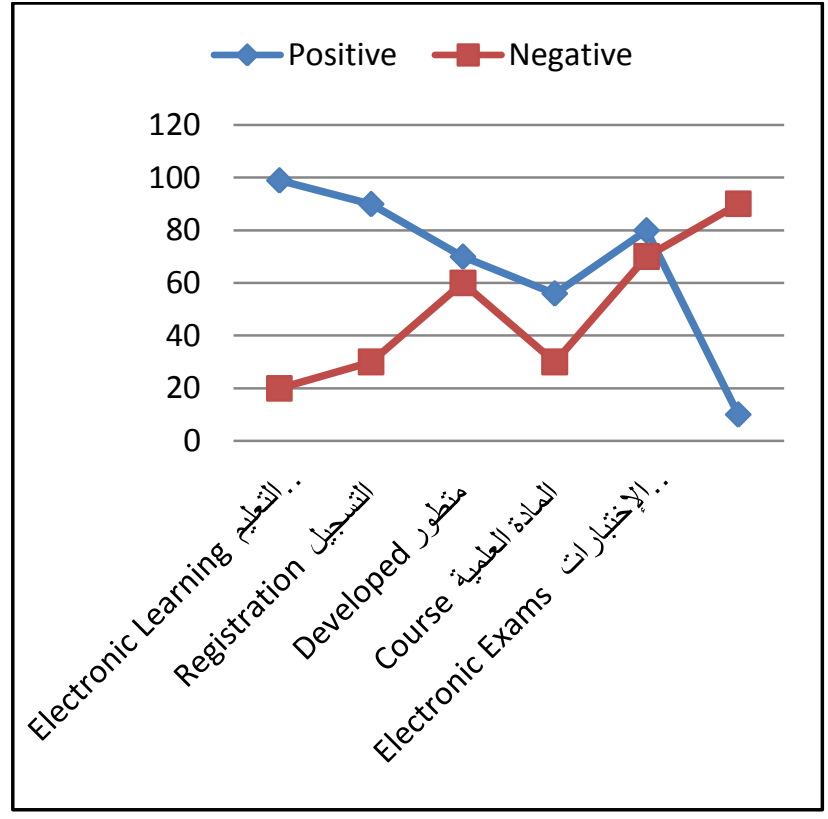

Figure 2. Visualization summary of sentiments about "التعليم الإلكتروني Electronic Learning"

In this example to explain this form of summary, which was summarize a set of sentiments of Electronic Learning التعليم "الاكتروني. The summary the same as that in Figure 1, which is called a structured summary which is not similar of a regular text summary of a short document generated from one or set of documents. In the figure, "التعليم الالكتروني مطور و فعال." The e-learning developed and effective "represents the e-learning (the entity). 99 reviews presents positive sentiments about the e-learning and 20 presents negative sentiments The scientific course availability and The electronic exams are two features about the e-learning. 56 reviews presents positive sentiments about The scientific course availability, and 30 presents negative opinions. <Particular review sentences> is a relation refers to the sentences and the whole reviews that present the sentiments. With like this a summary, student can simply see how existing students feel about the e-learning " التعلم

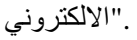

If any student is attracted in a specific feature and in more details, he/she can read by following the <Particular review sentences $>$ is a relation to see the real sentiments sentences or reviews.

In figure 2, the Visualization consisted of basically Students, Such insights were extremely important. They enabled the student to see the sentiments of different Students.[8]

\section{VARIOUS TYPES OF SENTIMENT}

There are two types of sentiments that will discussed so which is called regular sentiment And second type is called comparative sentiment. And also classify sentiments depends on how they are expressed in text, explicit sentiment and implicit (or implied) sentiment.

- Regular sentiment: It is indicates to basically as an sentiment in the literature and it has two sub-types:

Direct sentiment: A direct sentiment indicates to an sentiment explicit directly on an entity or an entity features for example: "Electronic exams is reliable "الاختبار ات الالكترونية كذلك موثقة" ,"

Indirect sentiment: An indirect sentiment is an sentiment that is explicit indirectly feature on an entity depends on its effects on some other entities. For example, the sentence "After take of the medicine, my head felt good " بعد تناولي للدواء "شعرت بتحسن في رأسي of the medicine on "my head", which indirectly gives a positive sentiment to "الدواء" the medicine. And the entity is the medicine and the feature is "تأثيره على الرأس " the effect on head, most of the current research focuses on direct sentiments.

- Comparative sentiment: is explicit a relation of similarities or differences between two or more entities and importance of the sentiment holder depends on some features of the entities. For example, the sentences, "Sami looks taller than Ali", "سامي يبدو أطول من علي" and "Sami looks the tallest", "سامي يبدو الأطول علي النول". explicit two comparative sentiments. A comparative sentiment is regularly expressed using the comparative or superlative form of an adjective or adverb.

- Explicit sentiment: is a subjective statement that make a The comparative sentiment, for example:

"Sami looks happy,","سامي يبدو سعيداً" and

"Sami looks taller than Ali", " سامي يبدو أطول من "سلعيد"

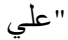


- Implicit sentiment: is an objective statement that implies a comparative sentiment. Such an objective statement generally expresses a desirable or undesirable thing,

For example:

"I brought the plants a month ago, and a garden has decorated,"

"أحضرت النباتات قبل شهر , و الحديقة تزينت"

And "The battery life of Mac book laptops is longer than Sony laptops."

$$
\text { " عمر بطارية أجهزة الماك بوك , أطول من أجهزة سوني " }
$$

Explicit sentiments are simple to detect and to classify that implicit sentiments.[8]

\section{SENTENCE SUBJECTIVITY AND SENTIMENT CLASSIFICATION}

Here with work on the sentence level by classify sentiment expressed in each sentence. The researchers guess about sentence level analysis is that a sentence regularly consist of a single sentiment. For example:

"I brought Laptop two months ago. In the beginning everything was great

The screen was clear and the battery life was long, although it is a bit heavy. Then, it stopped working yesterday."

$$
\begin{aligned}
& \text { أحضرت لابتوب قبل شهرين, في البداية كان كل شيء رائع," } \\
& \text { الثاثة كانت واضحة وعمر البطارية كان طويل, بالر غم أنه كان ثقيل. } \\
& \text { " ثم توقف عن العمل بالأمس }
\end{aligned}
$$

The first sentence presents no sentiment at all . But all other sentences presents between explicit or implicit sentiments. Also no sentiment is regularly classified as neutral.

The problem: For example a sentence $S$, determine whether $S$ gives a positive, negative, or neutral (no sentiment).

The elements $(e, \mathrm{f}, o, h, t)$ because of the classification in sentence level is an middle step so the definition is not used here. It is necessary knowing that a sentence may presents a positive or negative sentiments, but not what features the sentiment is about. Classification in the sentence level is functional because if knowing what entities and entity features are spoke about in a sentence, this step can assist determine if the sentiment about the entities and their features are positive or negative. classification in the sentence sentiment can be solved may as problem in one class or as two separate classes problem. In addition, the first problem is to classify whether a sentence expresses an sentiment or not. The second problem then specify those sentiment sentences are positive or negative classes. Subjectivity classification is presents the first problem, which determines whether a sentence gives a piece of subjective information or objective information. Objective sentences are expressing no sentiment.

For example, "Then, it stopped working yesterday", ثم نوقف عن

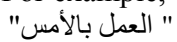

in the previous example is an objective sentence, but it presents a negative sentiment about the laptop because of the undesirable thing. so, it is more suitable for the first step to classify each sentence as sentiment or not sentiment, and if it is subjective or objective. When use the term subjectivity classification in this example. It will suitable discuss and classify the subjectivity of sentence level and then classify the sentiment.[8]

\section{A. Subjectivity Classification}

Subjective and objective are two types of the sentence Subjectivity classification. The difference between them the subjective sentence presents personal sentiments but the objective sentence regularly presents precisely information.

Opinions, evaluations, emotions, beliefs and judgments are examples of subjectivity classification in the sentence which present different types of information

By depending on supervised learning there are many of domains of subjectivity classification some of them indicate to positive or negative sentiments.

There are some essential methods for subjectivity classification, which essentially used the presence of subjective expressions to decide the subjectivity of the sentence.

Grade ability is one of a semantic property that select a word to appear in a comparative construct and to accept modifying expressions which work as intensifiers or diminishes. Gradable adjectives present properties in changing grade of strength, relative and a norm as clearly mentioned or clearly supported by the noun, for example: (a small planet is usually much larger than a large tower). ( الكوكب الصغير حجمه أكبر بكثير (a)

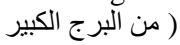

Gradable adjectives were found using a element list of specific adverbs and noun phrases such as a small, large, approximately, something, and very that are normally used as grading modifiers. Such gradable adjectives are good indicators of subjectivity.

The sentence similarity method is another semantic property performed subjectivity classifications using sentence similarity which depends on the assuming that subjective or sentiment sentences are more similar to other sentiment sentences than to factual sentences. They used the SIMFINDER system in to determine the sentence similarity depends on shared words, phrases. The sequences of sentiment words "++" for two successive positive oriented words, and "JJ+" for successive positive adjective.

If It classified the subjectivity of tweets which postings on Twitter social website depends on classic features and includes some Twitter specific tools like retweets, hashtags, links, upper case words, emoticons, and punctuations. For sentiment classification of subjective tweets, the same set of features was also used.[8]

\section{B. Sentence Sentiment Classification}

If a sentence is classified as specific subjective, It will represent a positive or negative sentiment. The sentiment holder used to give a specific sentiment from the sentence. This section is suitable for simple sentences with one sentiment, e.g.,

"The natural color of this flower is amazing." " اللون الطبيعي لهذه "الوردة for complex sentences, a single sentence may present more than one sentiment. For example, the sentence, "The natural color of this flower is amazing and also the smell beautiful, but the petals is too small for such a great flower,"

اللون الطبيعي للوردة مذهلة و ايضاً الر ائحة جميله. لكن البتلات جداً صغيرة"

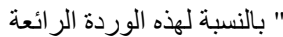

expresses both positive and negative sentiments .For "natural color" "اللون الطبيعي"and "smell beautiful," 
"الرائحة الجميلة" the sentence is positive, but for "petals," "البناتلات" it is negative. It is also positive about the flower.

The sentiment degree of a sentence was decided by totally the degree scores of all sentiment terms in the sentence. A positive term have the sentiment grade of +1 and a negative term have the sentiment grade of -1.[8]

\section{Dealing with Conditional Sentences}

A lot of the available researches on sentence subjectivity classification and sentiment classification focused on solving the problem without taking into consideration the difference between types of sentences may need very different procedures. So, It is not suitable to have a one method and use it for all solutions because various types of sentences present sentiments in very different ways. For example: A divide and conquer technique may be used.

The conditional sentences have some characteristics that make it complex for a system to specify the sentiment degrees. And it discussed a lot in current researches. Their combination has essential effect on where the sentence present a positive or negative sentiment.

The basic consideration is that sentiment words (e.g., good, great, nice, beautiful, bad, terrible) only cannot differentiate an sentiment sentence from a non- sentiment one, For example: "If The author published an interesting book, I will read it"

" إذا الكاتب نشر كتاب مثير للاهتمام, سوف اقر أه "

and "If your hp printer is not good, buy canon printer."

$$
\text { " canon غير جيدة اشتر طابعة hp إذا طابعة" }
$$

The first sentence present no sentiment towards any particular book, although "interesting" "مثير للاهتمام" is a positive sentiment word, but the second sentence is positive about the canon printer and it does not present an sentiment about the hp printer.

To determining sentiments in non conditional sentences by using special methods. These methods not suitable to used for conditional sentences. In this domain It deals with the problem using a set of linguistic characteristics, e.g., sentiment words, phrases and locations,

Part Of Speech tags of sentiment words, tense, conditional sentences, etc. The question sentence is type of complex sentences . For example,

"Can anyone tell me where I can find a good canon printer?"

$$
\text { " هل يسنطيع أحد اخباري أين استطيع أن اجد طابعة canon جيدة ؟ " }
$$

obviously has no sentiment about any particular printer. so,

"Can anyone tell me how to repair this lousy hp printer?"

$$
\text { " هل بسنطيع أحد اخباري كيف أصلح طابعة hp الرديئة؟ " }
$$

has a negative sentiment about the hp printer. To my knowledge, there is no study on this problem. I consider that for more accurate sentiment analysis, I need to deal with various types of sentences differently. Much further researches is consider in this direction.[8]

\section{THE SENTIMENT HOLDER} DEFINITION AND TYPES

To identify the sentiment holder as an expression in the text by determine if it is explicit or implicit in text or the Holder's positive, negative, or neutral according to the Topic. The Sentiment holder always involve emotions, feeling, opinion or desires. For example:

"اعتقد أن تعقيد الامتحان يضع الطلاب في وضع صعب"

"I think that complicating the exam would put the students in a difficult position" (The holder implicit)

"العنف في المدرسة مرفوض"

"The violence in school is rejected"

(The holder is explicit)

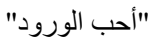

"I like the flowers"

(The holder is explicit)

"يجب أن نزيد جهودنا للامتحان"

"We should increase our efforts for the exam" (The holder implicit) [3]

The sentiment holder is the human or organization that introduce the sentiment. So, sentiment holders are regularly the author of the text and more important in news and articles because which explicitly specify the person or organization that presents a specific sentiment.[9]

For example this topic "Should Hunting be prohibited?" and a set of texts about the topic, find the Sentiments presents about the Topic in each text, and identify the people who hold each sentiment. For example, given the topic "What should be done with failure in math?"

"ما الذي ينبغي عمله مع الرسوب في الرياضيات؟"

the sentence: " After a lot of hard efforts, the head of the department has rolled out two student proposed plans, one from The department professors and the other from the Student Deanship."[3]

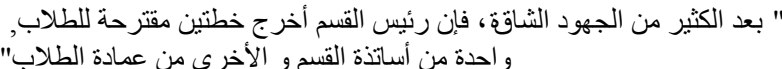

To avoid the problem of confusion in sentiments, It can solved the problem by: specify just terms of positive, negative, or neutral sentiments, together with their holders. Also, for sentences that don't present a sentiment but basically specify that some sentiments exists, return these sentences in a separate set.

By Solve the problem in sequenced stages, initialing with words in the sentence and take it as unit called the sentiment holder, Then classify each word to adjective, verb, and noun as a sentiment. By using several classifiers the words are experimented. [1]

\section{PROPOSED SENTIMENT HOLDER ALGORITHM}

The algorithm works in these steps:

The input: the article or a set of texts in Arabic Language.

1. The input text partitioned in to set of segments.

2. After segmentation Part of speech tagger and (Word Net) is preprocessing the segments into various speech like relationship with adjacent and related words in a phrase, sentence, or paragraph.[14]

3. The sentiment classifier take the sentiment as a single word. 
4. The output of sentiment classifier classify each adjective, adverb, phrase, verb, and noun by its sentiment.

5. Finally: The sentiment polarity test each word:
a. If the result zero, It means negative sentiment.
b. If the result one, It means positive sentiment.
c. And if the result neutral it means take next sentence.

In Figure 3 shows the System structural design includes steps to recognize the sentiment holders.

Some words have both positive and negative sentiment. For these words, it is difficult to specify one sentiment without considering context. It is more difficult to specify the sentiment correctly, especially if one of the words falls outside the sentiment location. Even in a single sentence, a holder might present two different sentiments. The system only detects the closest one.[3]

The following are two example outputs:

The Student team in Secondary school have the leader vote Thursday to exclude uncooperative members form the club saying the decision will help school save dollars of the club for the student activities.

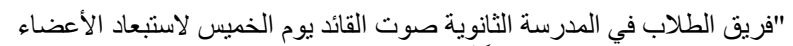

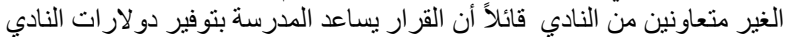

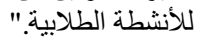

TOPIC : uncooperative members "الأعضاء الغير متعاونين"

HOLDER : The leader "القائد"

SENTIMENT_POLARITY: negative

For that reason and others, the students support unanimously this decision and the First meeting soundly suggest two affective term-limit proposals.

$$
\text { و الذلك السبب و غيره دعم الطلاب بالإجماع هذا القرار الأول أقترح على نحو سليم مقترحين فعالة محدودة الأجل" }
$$

TOPIC : term limit "مدود الأجل

HOLDER : First meeting "المؤتمر الأول"

SENTIMENT POLARITY: positive

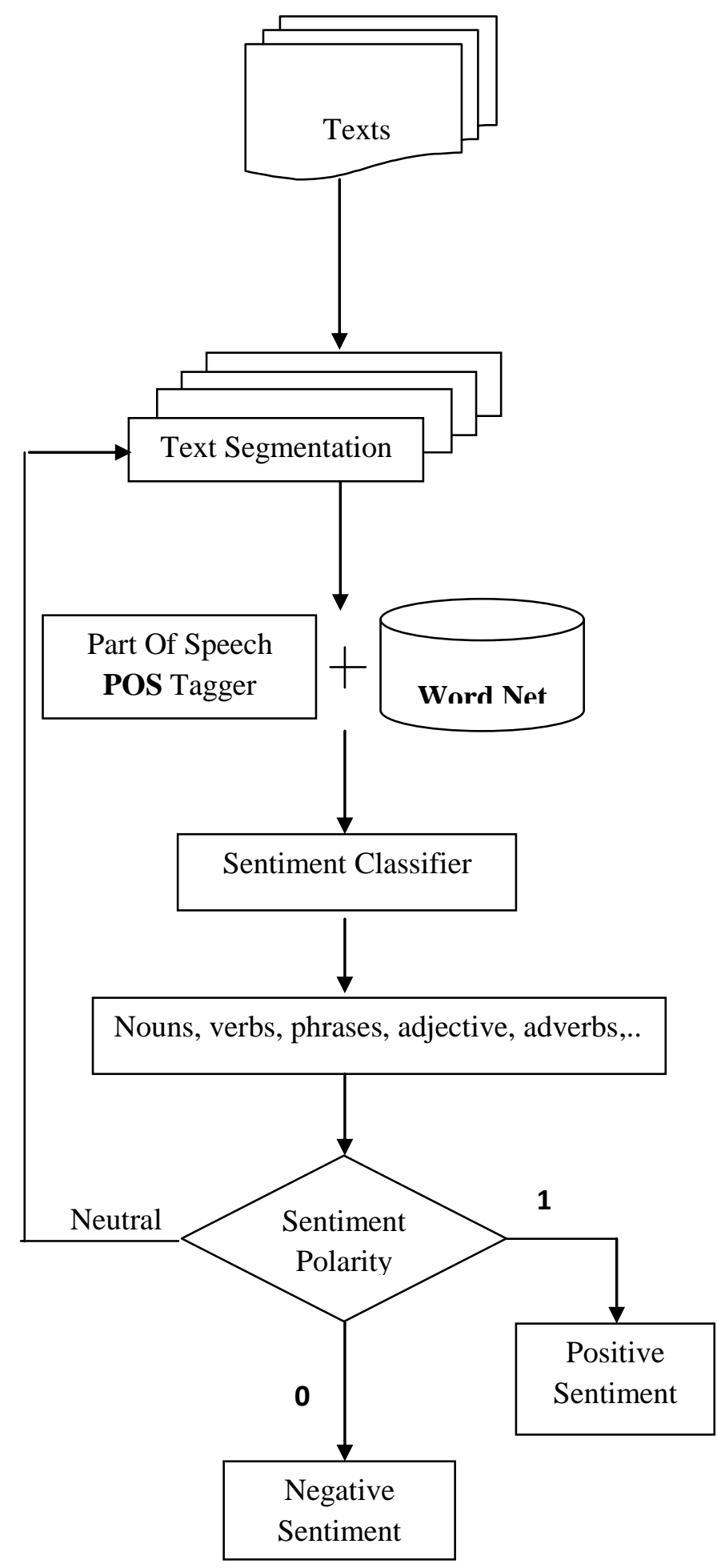

Figure 3: System structural design.

For sentences if It have more than one Holder, by select the closest one to the Topic phrase, for simplicity. This is a very simple step. A more improved method would use a parser to identify syntactic relationships between each Holder In analyzing the text of news or articles, It needs to identify text corresponding both to sentiment holders and to expressions of the sentiment.[11][10]

However, that the degree of an sentiment holder decided by definition of the expression of an sentiment.[12] 


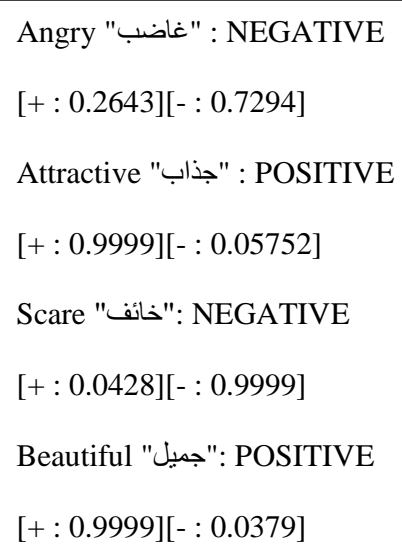

Figure 4: Sample output of word sentiment analysis

In Figure 4 shows different examples of the system output, computed with the equation, in which + gives positive type and - gives negative type. The word "Beautiful" was classified as presents positive sentiment, and "Scare" "خائف" presents as negative. The absolute value of each type represents the value of the sentiment polarity. E.g, "Scare" "خائف with value -0.99 represents high negative while "Angry" "غاضب" with value -0.72 represents low negative.[3]

\section{EXTRACTING THE SENTIMENT HOLDER}

The sentiment holders are information in sentences, so after specify the sentiment polarity It can extract the sentiment holder of the given sentence. First identify all possible sentiment holders in the sentence and recognize the holder:

1. It may person, Organization or location.

2. It must be specified as entity.

3. It always comes in the beginning of a sentence or near the beginning or at the end of the sentence.

4. The types of entities "name of person", "name of location" or "name of institution"

The holder may be a word or sequence of words, after the word detected it will be the actual holder.[6]

\section{CONCLUSION}

This paper presents Arabic sentiment holder which is a challenging and difficult part of understanding and specifying in the sentence. This survey discussed the recent researches in sentiment analysis. And the sentiment analysis operations, summarization and classification and proposed sentiment holder algorithm to extract sentiments from the sentences.

In a future study, we will concentrate more on the new algorithms helps to improve the accuracy of the results in analysis the sentence and specifying and extracting the sentiment holder.

\section{REFERENCES}

[1] Taysir Hassan A. Soliman, M. Ali M.Abdel Rahman Hedar, M. M. Doss, "MINING SOCIAL NETWORKS' ARABIC SLANG COMMENTS". In Proceedings of IADIS European Conference on Data Mining 2013 (ECDM'13), 22 - 24 July, Prague,Czech Republic

[2] Elarnaoty M. A Machine Learning Approach for Opinion Holder Extraction in Arabic Language. International Journal of Artificial Intelligence \& Applications. 2012;3(2):45-63.

[3] Mariana Vunvulea and Ioana Maria Sima. (02013 IEEE "A Rule-based, Domain Independent Approach for Opinion and Holder Identification"

[4] Aldo Gangemi,Valentina Presutti a":nd Diego Reforgiato Recupero, "Frame-Based Detection of Opinion Holders and Topics: A Model and a Tool", IEEE Computational intelligence magazine | February 2014

[5] Mohammed Korayem, David Crandall, and Muhammad Abdul-Mageed, "Subjectivity and Sentiment Analysis of Arabic: A Survey"

[6] Zhang Y, Long F, Bin L. Identifying Opinion Sentences and Opinion Holders in Internet Public Opinion. 2012:1668-71.

[7] Boyd dm, Ellison NB. Social Network Sites: Definition, History, and Scholarship. Journal of Computer-Mediated Communication. 2007;13(1):210-30.

[8] Bing Liu, Sentiment Analysis and Opinion Mining Book. April 22, 2012

[9] Hsinchun Chen and David Zimbra, AI and Opinion Mining, University of Arizona $(2010$ IEEE intelligent systems. Published by the IEEE Computer Society

[10] Hsinchun Chen, AI and Opinion Mining, Part 2 , University of Arizona, (C) 2010 IEEE intelligent systems Published by the IEEE Computer Society.

[11] Erik Cambria, Björn Schuller, Yunqing Xia, Catherine Havasi, New Avenues in Opinion Mining and Sentiment Analysis. () 2013 IEEE. Published by the IEEE Computer Society.

[12] Bo Pang and Lillian Le, "Opinion mining and sentiment analysis" .2008 Bo Pang and Lillian Lee. The a prepublication version .

[13] T. Wilson, J. Wiebe, and P. Hoffmann. "Recognizing contextual polarity in phrase-level sentiment analysis. In Proceedings of the conference on Human Language Technology and Empirical Methods in Natural Language Processing", pages 347-354. Association for Computational Linguistics, 2005.

[14] Jerome R. Bellegarda," Part-of-Speech Tagging by Latent Analogy" , IEEE JOURNAL OF SELECTED TOPICS IN SIGNAL PROCESSING, VOL. 4, NO. 6, DECEMBER 2010 